\title{
Políticas de Educação Especial e Inclusão no Estado do Rio de Janeiro: formação de professores e organização da escola pública ${ }^{1}$ Valdelúcia Alves da Costa ${ }^{2}$
}

\section{RESUMO}

Políticas de Educação Especial e Inclusão no Estado do Rio de Janeiro: formação de professores e organização da escola pública. Este texto é resultante do projeto de pesquisa "Políticas públicas de educação especial no Estado do Rio de Janeiro: desafios da inclusão escolar de alunos com deficiência”, com apoio da CAPES, por intermédio do Edital PROESP/2009, desenvolvido nos municípios-polo do Estado do Rio de Janeiro. Seus objetivos são: caracterizar a acessibilidade arquitetônica, curricular e pedagógica das escolas; identificar os impactos das políticas de educação especial na aprendizagem dos alunos com deficiência incluídos; e, avaliar as experiências pedagógicas dos professores e suas atitudes frente aos alunos com deficiência. Este estudo avalia o processo de democratização da escola na perspectiva da Teoria Crítica da Sociedade, tendo nessa etapa como sujeitos 26 professores do Colégio Estadual Duque de Caxias, localizado no município de Duque de Caxias, tendo como instrumentos de coleta de dados: questionários, entrevistas semiestruturas, observações no cotidiano escolar, oficinas de narrativas docentes, e as categorias de análise: educação e autonomia docente; formação, educação e inclusão escolar; atitudes docentes e a manifestação do preconceito, dentre outras. Os resultados obtidos revelaram que tanto a formação inicial quanto os programas de formação continuada pouco têm contribuído para os professores pensarem a inclusão como capaz de educar alunos com deficiência no mesmo espaço escolar junto com os demais alunos, na superação da segregação na escola pública. Também foi observado que a maioria dos professores é favorável à inclusão escolar, embora afirmando que a reestruturação das escolas é primordial para que a educação inclusiva seja efetivada, sem referência à autonomia docente como central na democratização da educação na escola pública.

Palavras-chave: Políticas de Educação Especial; Inclusão Escolar; Formação de Professores.

\section{ABSTRACT}

Special Education and Inclusion Policies in Rio de Janeiro: teachers' formation and public school organization. This text is the result of the research project "Public Policies for Special Education in Rio de Janeiro: challenges of school inclusion of students with disabilities". It was developed in Rio de Janeiro municipalities with CAPES' financial support through

1Este texto é resultante do projeto de pesquisa "Políticas públicas de Educação Especial no Estado do Rio de Janeiro: Desafios da inclusão escolar de alunos com deficiência”, financiado pela CAPES.

2 Professora Associada, Universidade Federal Fluminense, Faculdade de Educação, Programa de Pós-Graduação em Educação, Pesquisadora da CAPES. E-mail: valdelucia2001@uol.com.br 
PROESP/2009 Edict. Its objectives are to characterize the architectural, curricular and pedagogical accessibility at schools, to identify the impacts of special education policies on the learning of included disabled students, and to evaluate the teacher learning experiences and their attitudes in dealing with those students. This study evaluates the school democratization process based on the Critical Theory of Society. Its participants are 26 teachers who work at Duque de Caxias State School, an institution located in Duque de Caxias/RJ. As instruments of data collection, the researches used questionnaires, semiestructured interviews, school routine observation, teacher narratives' workshops and categories of analysis such as: education and teacher autonomy, training, education and school inclusion, teacher attitudes and the prejudice manifestation, among others. The results revealed that both initial training and continuing education programs did not contribute a lot to teachers think about inclusion as a way of educating disabled students with ordinary students in order to overcome segregation at public schools. It was also observed that although most teachers agree with school inclusion, they notice that schools' structure is important to inclusive education effectiveness, but did not mention teaching autonomy as central to the democratization of education at public schools.

Key words: Special Education policies; school inclusion; teacher education.

\section{INTRODUÇÃO}

Este texto refere-se à apresentação dos resultados obtidos no projeto de pesquisa "Formação de Professores e Educação Especial: inclusão de alunos com deficiência nas escolas públicas do Estado do Rio de Janeiro", financiado pela CAPES e desenvolvido em Duque de Caxias, município situado na Baixada Fluminense, Estado do Rio de Janeiro, com uma população estimada em 855.046 habitantes, de acordo com relatório do IBGE (2010).

Atualmente, a formação de professores e a inclusão escolar têm assumido prioridade nas pesquisas, debates acadêmicos e políticas públicas de Educação Especial. Isso é relevante ser destacado face ao longo período de exclusão social imposto às pessoas com deficiência, considerando que o direito de acesso à educação e permanência na escola pública, como nas demais instâncias sociais, foi historicamente obstado e diante da urgência em se estudar a relação entre formação e preconceito, embora "a formação do indivíduo ocorre na relação sujeito-objeto e a distinção entre esses dois polos e a predominância de um deles sobre o outro apresentam problemas na sua constituição" (CROCHÍK, 2011, p. 19).

Dessa maneira, de acordo com Costa (2011, p. 65), “(...) o processo de inclusão de alunos com deficiência, deve ocorrer no interior da escola como espaço sócio-democrático", no qual o acesso ao conhecimento contribui para o reconhecimento da diferença como essência da humanidade, a solidariedade, a manifestação da criatividade, como também para a troca solidária de experiências, considerando que a escola como espaço inclusivo deve promover a remoção 
das barreiras à aprendizagem, deixando de enfatizar as deficiências dos alunos como obstáculo, destacando, sobretudo, sua humanidade e, consequentemente, seu direito à educação escolar e o acesso ao conhecimento em espaços escolares democráticos.

Mais especificamente, este estudo teve por objetivo geral avaliar os impactos das políticas públicas de Educação Especial na perspectiva da inclusão nas escolas regulares, considerando a formação dos professores e organização da escola na rede pública de ensino do Estado do Rio de Janeiro, no Município de Duque de Caxias.

Nessa direção este estudo teve por objetivos: a) avaliar os impactos das políticas públicas de Educação Especial com vistas à inclusão escolar de alunos com deficiência nas escolas estaduais do Rio de Janeiro, no Município de Duque de Caxias; b) caracterizar a atuação docente dos professores quanto às necessidades educacionais especiais e à educação inclusiva de alunos com deficiência na escola regular; c) identificar as adaptações pedagógicas, curriculares e arquitetônicas na escola estadual, no Município de Duque de Caxias, implementadas em decorrência das políticas públicas de Educação Especial na perspectiva da inclusão de alunos com deficiência; d) reconhecer os aspectos que ainda permitem a segregação na escola pública, considerando o Atendimento Educacional Especializado/AEE na Sala de Recursos Multifuncionais/SRMs.

Participaram dessa pesquisa 26 professores/as da rede estadual de ensino do Município de Duque de Caxias, Estado do Rio de Janeiro, que atuam no Colégio Estadual Duque de Caxias e vivem experiências de inclusão em suas salas de aula. Os resultados referem-se às impressões e à identificação das atitudes dos/as professores/as quanto à educação inclusiva dos alunos com deficiência na escola pública com base em suas experiências docentes e à caracterização das adaptações curriculares que permitem o acesso à aprendizagem e a democratização da escola pública na perspectiva da educação inclusiva, ou seja, uma educação emancipadora capaz de combater o preconceito na escola, por intermédio de um projeto pedagógico que contemple as diferenças de aprendizagem dos alunos, resultantes de suas deficiências cognitivas, sensoriais e físicas, não as transformando em desigualdade. Na realização deste estudo foram utilizados os seguintes procedimentos, instrumentos de coleta e análise de dados:

$1^{\circ}$ ) questionários - para caracterização dos (as) professores (as) como escola onde atuam; série, nível ou área de atuação; data de nascimento; formação; sexo; tempo de serviço em educação, dentre outros dados.

$\left.2^{\circ}\right)$ entrevistas semiestruturadas - contendo questões acerca de inclusão escolar de alunos com deficiência em classes comuns, tais como: 
- o que você pensa sobre a inclusão de alunos com deficiência em sua sala de aula?

- qual a sua opinião sobre alunos com deficiência estudarem junto com colegas sem deficiência na mesma sala de aula?

- sua escola está organizada para a inclusão de alunos com deficiência nas classes comuns, no que se refere aos aspectos de:

- acessibilidade: rampas, banheiros adaptados, portas largas, mobiliário adaptado, dentre outros aspectos?

- recursos: materiais e pedagógicos para as necessidades educacionais especiais dos alunos com deficiência?

- comente como você se sente atuando em classes inclusivas, ou seja, classes com alunos com deficiência e sem deficiência aprendendo juntos.

$3^{\circ}$ ) observações do cotidiano escolar - para identificação das adaptações curriculares e pedagógicas, como também atitudes dos professores quanto ao acolhimento, inclusão, atendimento, resistência e segregação em relação às necessidades educacionais especiais dos alunos com deficiência incluídos nas salas de aula.

$4^{\circ}$ ) dinamização de "Oficinas de Narrativas de Experiências Docentes" - nas quais os professores discutem suas experiências de inclusão dos alunos com deficiência em suas salas de aula, como também suas dúvidas, anseios, desafios e as adaptações pedagógicas e curriculares adotadas na educação inclusiva.

$5^{\circ}$ ) categorias de análise - para a análise dos dados coletados nas entrevistas semiestruturadas, nas observações do cotidiano escolar e nas Oficinas de Narrativas de Experiências Docentes, foram consideradas categorias baseadas na Teoria Crítica da Sociedade, tais como educação e emancipação; educação e adaptação social; educação e desenvolvimento da autonomia, da sensibilidade, da resistência; educação e contradições sociais; educação e inclusão escolar; preconceito, indivíduo e cultura, entre outras.

\section{RESULTADOS E DISCUSSÃO}

No alcance dos objetivos foram considerados os estudos dos pensadores da Teoria Crítica da Sociedade, como Adorno e Horkheimer, entre outros autores que versam sobre formação, educação e preconceito, como também os documentos oficiais, nacionais e internacionais que preconizam a Educação Especial na perspectiva da inclusão escolar na atualidade. No desenvolvimento da pesquisa no Município de Duque de Caxias/RJ, foram sujeitos do estudo 26 professores (as) que atuam no Colégio Estadual Duque de Caxias, com formação mínima necessária ao exercício do magistério, ou seja, Nível Médio em Curso de Formação de Professores, 
sendo que a maioria com licenciatura em Pedagogia, Letras, Matemática e Pós-Graduação em Gestão do Trabalho Pedagógico, sendo que todos declararam o desejo de continuar os estudos em nível de pós-graduação.

Quanto ao que pensam sobre a inclusão de alunos com deficiência em classes regulares, os professores (as) afirmaram:

Boa iniciativa, pois eles precisam ter os mesmos direitos dos outros de estudarem. Quanto a estudarem na mesma sala, é bom em parte, pois eles passam a sentir-se parte do grupo. Mas para o professor, é muito difícil e trabalhoso, pois precisam de maior assistência. (Prof. Sara)

Acho válido, desde o momento que haja paralelamente um acompanhamento especial para os mesmos. (Prof. ${ }^{a}$ Márcia)

Considerando as respostas, verifica-se que essas professoras encontram-se ainda em uma fase de resistência à inclusão de alunos com deficiência por questões objetivas e pedagógicas, por não se sentirem preparadas para atuar em classes inclusivas. Portanto, com base nas narrativas acima, é possível afirmar que a inclusão de alunos com deficiência na escola pública está ocorrendo, porém demanda suporte aos professores. Daí a necessidade de implementação da educação inclusiva com planejamento para suas diversas etapas, desde a formação dos professores até a organização pedagógica da escola, para que se constitua em um processo de enfrentamento e de encaminhamento das propostas, dos programas e de adoção de princípios pedagógicos entendidos e acolhidos pelos professores, envolvidos diretamente no ensino e na avaliação da aprendizagem dos alunos, com respeito às minorias historicamente excluídas das instâncias sociais que neste estudo tem a escola pública como locus privilegiado. Assim, a inclusão escolar e social é um processo que deve, cada vez mais, ampliar o acesso aos bens culturais, promovendo a participação dos alunos e professores, com base em princípios políticos democráticos, isto é, independentemente de raça, cor, sexo, religião, condição física e/ou cognitiva ou condição social dos alunos com e sem deficiência.

\section{Educação inclusiva e formação de professores}

O reconhecimento da diferença como marca da humanidade e o compromisso dos professores no atendimento às diferenças de aprendizagem dos alunos em sua prática docente apontam para a importância de uma formação que os sensibilize para a atuação em salas de aula inclusivas, embora “(...) isso se faz necessário para a humanização das relações de ensino e aprendizagem na escola pública, ou seja, as relações entre os professores e seus alunos, na busca da superação de uma educação homogeneizadora” (COSTA, 2011, p. 45). 
Os professores, ao assumirem o compromisso de atuar em suas salas de aula na perspectiva da educação inclusiva, demandarão o aprendizado do acolhimento de diferentes alunos, buscando assim compreender, enfrentar e superar os estereótipos existentes em relação às minorias, no caso, os alunos com deficiência, procurando nos desafios as perspectivas de uma escola pública que seja democrática e aberta à diversidade dos alunos, tendo isso como princípio norteador de sua práxis pedagógica inclusiva.

Outro fator importante na inclusão de alunos com deficiência é a oportunidade do convívio com colegas sem deficiência, oportunizando àqueles perceberem-se como indivíduos capazes de se desenvolver em suas diferentes dimensões, tais como a social, psíquica, biológica, econômica e espiritual. Para tal, de acordo com Costa (2007, p. 260), “deve-se, então, buscar meios para a organização de escolas inclusivas, contribuindo, dessa maneira, para que os alunos com deficiência alcancem sua emancipação, por intermédio de uma educação transformadora e democrática.” Pensar a educação nessa perspectiva é admitir que alunos com deficiência e sem deficiência não são meros expectadores e que podem aprender juntos, ou seja, uma educação na qual a aprendizagem não ocorra em contextos segregados, mas perceber nos alunos, pela experiência com os mesmos, possibilidades de aprendizagem para todos em salas de aula acolhedoras e solidárias. Professores dispostos a viverem experiências com as diferenças humanas de seus alunos contribuem para o desenvolvimento de práticas docentes fundamentadas na reflexão crítica e na autonomia.

As narrativas dos (as) professores (as) são reveladoras quanto à importância da inclusão de alunos com deficiência nas salas de aula regulares, como também a importância do convívio com a diversidade humana, como destacado pelo Plano Nacional de Educação (BRASIL, 2010). Segundo o referido Plano, o ambiente escolar deve ser favorável à inclusão, à participação e ao convívio entre os alunos com e sem deficiência, sem separação de salas de aula. Isso proporcionará não apenas condições ao seu desenvolvimento e aprendizagem e à superação do caráter homogeneizador assumido pelos espaços especializados, espaços que segregam alunos com deficiência, considerados inaptos ao convívio na escola comum, obstando a experiência entre as diferentes subjetividades no ambiente escolar, bem como a necessidade de formação dos professores que contemple as questões inerentes ao processo de inclusão de alunos com deficiência não presentes em sua formação inicial:

Penso ser bastante importante para a formação do conhecimento conviver com as diferenças (Prof. ${ }^{a}$ Lívia).

O aluno portador de deficiência, seja ela qual for, não deve ser tratado como uma pessoa diferente das chamadas "normais" e sim como alguém com uma necessidade especial. Por este motivo, ele deve ser incluso em uma escola regular e estudar com alunos sem deficiência, pois o mesmo não vive em um mundo onde só há portadores de deficiência (Prof. ${ }^{a}$ Luiza).

Vivo esta experiência e com muito sucesso (Prof. ${ }^{a}$ Josiane). 
Segundo as narrativas das professoras, a presença de alunos com deficiência não dificulta o desenvolvimento e a aprendizagem de seus colegas sem deficiência. Quanto a isso, Crochík em seu projeto de pesquisa "Preconceito e Atitudes em Relação à Educação Inclusiva", relata que as “(...) crianças deficientes têm vantagens quando aprendem em conjunto com as crianças não deficientes e essas últimas não são prejudicadas.” Em outras palavras, a presença de crianças com deficiência não impede o desenvolvimento e a aprendizagem de seus colegas sem deficiência, assinalando também que “(...) se no ensino integrado/inclusivo os alunos deficientes tendem a imitar os alunos não deficientes, o que é vantajoso para eles, os alunos não deficientes não tomam os deficientes como modelo de imitação. Ao contrário, consideram como modelo as crianças não deficientes. Assim, as crianças deficientes têm vantagens no ensino integrado/inclusivo, principalmente no que se refere à sua sociabilidade.” Assim, conforme Crochík, isso revela as vantagens da educação inclusiva, quer para os alunos com deficiência, quer para seus colegas sem deficiência. Portanto, é importante considerar que a educação inclusiva é um avanço na questão da igualdade e da justiça social, mesmo considerando os limites sociais e os desafios de sua implementação presentes nas escolas da rede pública de ensino no Estado do Rio de Janeiro, revelando também os desafios aos professores para lidar com as necessidades educacionais especiais dos alunos com deficiência.

\section{Educação e desenvolvimento da autonomia docente}

No que se refere à autonomia docente, faz-se necessário problematizar as condições objetivas e materiais presentes tanto na formação do professor quanto em sua prática docente, pois no pensamento de Adorno (2002, p. 96) “(...) a submissão dos homens às formas vigentes da reprodução da vida”, tem contribuído para obstar essa problematização e, consequentemente, a possibilidade da atuação crítica docente tende a atrofiar-se face aos desafios postos à inclusão, como observado nas seguintes narrativas:

A inclusão é possível desde que haja uma preparação prévia onde professores e alunos tenham condições de se adaptar às novas situações com que irão se deparar, evitando que haja rejeição (Prof. ${ }^{a}$ Adriana).

Penso que determinados tipos de deficiência são difíceis de trabalhar em uma sala de aula com mais de vinte e cinco alunos sem deficiência. É preciso que o professor tenha habilidade e competência para realizar este tipo de trabalho (Prof. ${ }^{a}$ Patrícia).

As narrativas das professoras revelam a necessidade de reflexão sobre suas concepções de educação inclusiva e práticas pedagógicas e a necessidade de autonomia docente para além da adaptação às exigências do currículo escolar, conforme Adorno (2000, p. 143): 
De um certo modo, emancipação significa o mesmo que conscientização, racionalidade. Mas, a realidade sempre é simultaneamente uma comprovação da realidade e essa envolve continuamente um movimento de adaptação.

Por outro lado, a possibilidade da autonomia docente não exime o professor de, tanto em seu processo formativo quanto em sua atuação docente, desconsiderar a adaptação preconizada por instâncias formativas, como a escola e o mundo do trabalho, pois segundo Adorno (2000, p. 143-144):

\begin{abstract}
A educação seria impotente e ideológica se ignorasse o objetivo de adaptação e não preparasse os homens para se orientarem no mundo. Porém, ela seria igualmente questionável se ficasse nisso, produzindo nada além de well adjusted people, pessoas bem ajustadas, em consequência do que a situação existente se impõe precisamente no que tem de pior. Nesses termos, desde o início existe no conceito de educação para a consciência e para a racionalidade uma ambiguidade. Talvez não seja possível superá-la no existente, mas certamente não podemos nos desviar dela.
\end{abstract}

Dessa maneira, a educação como categoria central na formação dos professores tem o potencial de apontar para além da adaptação, pois “a educação tem sentido unicamente como educação dirigida a uma auto-reflexão crítica.” (ADORNO, 2000, p. 121). Isso contribuirá para a identificação entre professores e alunos com deficiência na escola pública, pois “a incapacidade para a identificação foi sem dúvida a condição psicológica mais importante para tornar possível algo como Auschwitz em meio a pessoas mais ou menos civilizadas e inofensivas" (ADORNO, 2000 , p. 134). A educação inclusiva pode contribuir na identificação entre diferentes subjetividades, possibilitando experiências que combatam a manifestação do preconceito. Para tal, faz-se urgente a discussão sobre “(...) para onde a educação deve conduzir? Ou seja, que uma tal discussão geral acerca do objetivo da educação tivesse preponderância frente à discussão dos diversos campos e veículos da educação" (ADORNO, 2000, p. 139-140).

Nesse sentido, o enfrentamento da concepção de educação e a demanda por inclusão parecem agigantar-se diante dos desafios postos à formação dos professores e à organização da escola, sobretudo considerando o pensamento de Adorno (2000, p. 141-142), ao apresentar sua concepção inicial de educação que:

Evidentemente não a assim chamada modelagem de pessoas, porque não o direito de modelar pessoas a partir do seu exterior; mas também não a mera transmissão de conhecimentos, cuja característica de coisa morta já foi mais do que destacada, mas a produção de uma consciência verdadeira. Isso seria inclusive da maior importância política; sua ideia, se é permitido dizer assim, é uma exigência política. Isso é: uma democracia com o dever de não apenas funcionar, mas operar conforme seu conceito, demanda pessoas emancipadas. Uma democracia efetiva só pode ser imaginada enquanto uma sociedade de quem é emancipado.

Portanto, é possível afirmar que a educação inclusiva pode contribuir tanto para a formação de alunos emancipados quanto para o fortalecimento da democracia social brasileira. 


\section{Educação inclusiva de alunos com deficiência e adaptações curriculares}

Quanto às questões "sua escola está preparada para promover a inclusão escolar de alunos com deficiência no que se refere aos aspectos de acessibilidade, como rampas, banheiros adaptados, portas largas, mobiliário adaptado, entre outros aspectos e recursos materiais e pedagógicos para as necessidades educacionais especiais dos alunos com deficiência?”, dezenove professores afirmaram que não, somente uma professora respondeu que sim e as demais afirmaram que sua escola está preparada no que se refere à acessibilidade arquitetônica, por ser um CIEP, mas que há pouco material pedagógico adequado às necessidades educacionais especiais dos alunos com deficiência.

Quando questionados (as): sentem-se “(...) aptos (as) para atuar em classes inclusivas?”, dezenove professores (as) responderam que não, justificando que “(...) não obtiveram uma formação específica; porque o medo é maior; devido ao grande número de alunos em sala de aula, o que dificulta a atuação com os alunos que apresentam necessidades educacionais especiais; porque é um trabalho muito difícil”, entre outras respostas. Os (as) sete professores (as) que responderam afirmativamente, justificaram assim: “(...) a bagagem de experiências de anos vividos nos dá a simples passagem com essas classes, pois atuando com eles você não só ensina, mas também aprende".

Considerando as respostas, observamos que os (as) professores (as) são favoráveis à educação inclusiva, porém afirmam que a reestruturação das escolas é primordial para que a inclusão ocorra de maneira efetiva. Portanto, deve-se atentar para a superação das barreiras que dificultam o desenvolvimento e a autonomia dos alunos com deficiência. Diante do exposto até então, para além das dificuldades objetivas encontradas pelos professores pelo fato de não se julgarem aptos e/ou preparados para atuar em classes inclusivas, é possível afirmar que não há necessidade de estarem preparadas para atuar com as diferenças de aprendizagem dos alunos, pois os alunos, como seres humanos, apresentam subjetividade e singularidade e, portanto, encontram-se em constante diferenciação.

Os professores lidam cotidianamente com diferentes alunos nas salas de aula, sejam eles com ou sem deficiência. Assim, deveriam estar voltados à própria formação, tendo ou não alunos com deficiência em suas salas de aula. 
Portanto, a principal meta dos professores no processo de escolarização dos alunos com deficiência deve ser o atendimento de suas necessidades de aprendizagem no alcance da autonomia intelectual, moral, social e para que esses tenham a oportunidade de se diferenciarem como indivíduos na escola pública e na convivência com diferentes subjetividades de colegas com ou sem deficiência. Quanto a isso, Costa (2011, p. 559) destaca que:

\begin{abstract}
A formação dos professores deve abranger o desenvolvimento de sua sensibilidade, para que possam planejar de maneira flexível, adaptando sua prática pedagógica à demanda de seus alunos, considerando para tal novas possibilidades de atuação junto a eles.
\end{abstract}

Faz-se necessário que o professor desenvolva sua sensibilidade para a realização do trabalho pedagógico voltado ao atendimento dos alunos com ou sem deficiência. Isso significa pensar a educação não apenas como um processo contínuo de adaptação social, mas como formação cultural e humana. É necessário pensar que a formação de professores no atendimento às necessidades de aprendizagem dos alunos não contemple apenas métodos de ensino, estratégias pedagógicas e recursos tecnológicos. É preciso pensar para além disso, assumir uma postura investigativa e atitudes democráticas, na superação da ideia reducionista de formação unicamente para a produção e reprodução social, ou seja, para o mundo do trabalho.

Dessa maneira, a educação pode contribuir na conscientização dos professores a não se aterem somente a técnicas reducionistas, as quais fortalecem e reproduzem o pensamento estereotipado. Ao focar em técnicas, o professor não consegue desenvolver sua sensibilidade, não percebendo nos alunos com deficiência nada para além da aparência. Quando perguntados o que pensam sobre a inclusão de alunos com deficiência nas escolas públicas e de fato estudarem junto com os alunos sem deficiência na mesma sala de aula, os (as) professores (as) afirmaram:

É muito importante a inclusão de alunos com deficiência nas escolas e ainda mais necessária a presença dos nossos 'especiais' com alunos sem deficiência, pois assim haverá uma quebra de preconceitos (Prof. ${ }^{a}$ Dinar).

É muito importante para a melhor convivência e redução da exclusão. A inclusão se dá com os alunos juntos nas salas de aula, não se inclui separando (Prof. ${ }^{\circ}$ Liedson).

A inclusão é um grande salto que tentamos dar a cada dia. Acho importante a presença, em sala de aula, dos alunos com deficiência e sem deficiência (Prof ${ }^{a}$ Mariana).

De acordo com essas narrativas, é possível perceber que não há resistência em atuar com alunos com deficiência. Apesar de justificarem a "falta de tempo para os cursos de formação continuada", os (as) professores (as) reconhecem sua necessidade. Sendo assim, essas narrativas revelam que os (as) professores (as) percebem a importância da educação inclusiva e, com isso, a necessidade de aprimorar sua formação, porém "não encontram tempo para se dedicar a tal", além de admitir a dependência quanto à presença do intérprete de Libras, pois quando este não está presente na 
sala de aula, ocorrem dificuldades de comunicação e compreensão por parte dos alunos surdos e o professor da turma. O professor superestima a função do intérprete de Libras no cotidiano escolar, sentindo-se impotente e angustiado por ocasião de sua ausência, por não conseguir promover o acesso dos alunos surdos aos conteúdos curriculares.

\section{Educação inclusiva e desenvolvimento da autonomia de professores e alunos}

Mesmo considerando que o desenvolvimento de programas de formação continuada no Município de Duque de Caxias/RJ possa contribuir para tornar os professores aptos a viverem experiências de inclusão em suas salas de aula, por sua vez, não determinam que os mesmos se sintam preparados à inclusão. Nesse sentido, faz-se necessária a reflexão sobre a formação dos professores e seus conhecimentos frente aos desafios da educação inclusiva, posto que para Adorno (1995, p. 189), a “crítica da sociedade é crítica do conhecimento e vice-versa.”. Assim, a reflexão sobre tal questão contribui para o desenvolvimento da autonomia e resistência dos professores. Isso aponta para a possibilidade de organização da escola para o atendimento às demandas humanas por inclusão e participação social dos professores em prol da educação inclusiva dos alunos com deficiência.

Para tal, a alternativa para se afirmar a educação inclusiva e a formação para além da adaptação aos conteúdos curriculares, é contribuir para o fazer pedagógico crítico que possibilite o desenvolvimento da autonomia dos professores, fazendo frente às questões presentes nas narrativas abaixo que revelam os desafios postos ao professor na educação inclusiva dos alunos com deficiência:

A inclusão é possível desde que haja uma preparação prévia onde professores e alunos tenham condições de se adaptar às novas situações com que irão se deparar, evitando que haja rejeição (Prof. ${ }^{a}$ Adriana).

Penso que determinados tipos de deficiência são difíceis de trabalhar em uma sala de aula com mais de vinte e cinco alunos sem deficiência. É preciso que o professor tenha habilidade e competência para realizar esse tipo de trabalho (Prof. Patrícia).

As narrativas das professoras revelam a necessidade de reflexão sobre suas concepçóes de educação inclusiva e práticas pedagógicas com vistas à autonomia no exercício da docência, e como destacado por Costa (2010, p. 125):

Dessa maneira, a educação teria que contribuir para a conscientização dos professores e não se ater somente a técnicas reducionistas, que fortalecem e reproduzem o pensamento estereotipado. Ao focar em técnicas, o professor não consegue desenvolver sua sensibilidade, não percebendo nos alunos com deficiência nada para além da aparência. 
Ou seja, devemos atuar de modo a atender as necessidades de aprendizagem dos alunos e não com o foco em suas deficiências, essas historicamente utilizadas como instrumento de legitimação da exclusão e segregação impostas ideologicamente a esses alunos por grupos sociais hegemônicos. Antes, de acordo com Costa (2010, p. 525):

La mayor cuestión de las políticas de formación e inclusión es contraponerse a la segregación histórica de los niños y niñas en la escule pública con una postura crítica en relación a la función social y humana de la educación.

Para tal, faz-se necessário pensar e conhecer os alunos com deficiência em seu desenvolvimento de diferenciação como seres humanos aptos a viverem na diversidade social e de acordo com Costa, Barcellos, Faitanin \& Araujo (2010, p. 509-510):

Enfatiza el pensar la educación como un campo de conocimiento a ser ejercido por los maestros em forma reflexiva y crítica en el espacio escolar para todos los alumnos, aceptando y respetando su diversidad. Por tanto es necesario al pensar la formación de maestros y la educación de los alumnos com deficiencia una postura crítica en relación a la función social de la educación: um movimiento de acción político-reflexiva a ser ejercida con autonomía por los maestros en las escuelas democráticas.

Quanto a isso, Crochík (2009, p. 23) destaca que “(...) Adorno propõe que a educação vise à autonomia, à emancipação. Assim, é necessário que se volte às contradições sociais e não tentar negar sua existência; para isso deve ser, sobretudo, uma educação política”. Isso implica pensar a escola como local de formação de seres críticos, pensantes, capazes de contrapor-se a toda forma de manipulação e dominação imposta pela sociedade, sem de fato negar a existência de uma lógica vigente, mas ter a possibilidade de problematizá-la criticamente.

É de fundamental importância ter os pais presentes na escola para que possam participar do processo de inclusão de seus filhos. Como também é importante a organização de espaços de formação na escola para discussão e reflexão sobre a educação inclusiva, promovendo leitura de textos, vídeos educativos, documentários, palestras, contribuindo, dessa maneira, para o conhecimento dos profissionais da educação, dos pais e dos alunos sobre a educação inclusiva na escola pública, a fim de resistir à manifestação do preconceito e à segregação, resultantes da escassez de experiência com as diferenças humanas na escola e demais instâncias sociais. 


\section{Educação inclusiva e acessibilidade na escola pública}

Na última etapa do estudo no Município de Duque de Caxias, foi observado avanço nas questôes relativas à acessibilidade arquitetônica e pedagógica, como também no Atendimento Educacional Especializado/AEE nas Salas de Recursos Multifuncionais/SRMs aos alunos com deficiência incluídos nas escolas públicas. Para tal comprovação, foi observado que no Colégio Estadual Duque de Caxias há acessibilidade arquitetônica, material pedagógico e intérpretes de Libras, além das obras realizadas na melhoria da acessibilidade arquitetônica e pedagógica aos alunos com deficiência. Algumas adaptações arquitetônicas e pedagógicas no Colégio Estadual Duque de Caxias são: rampa de acesso ao refeitório; piso podotátil para orientação espacial de alunos cegos; porta larga para acesso de alunos com cadeira de rodas; Sala de Recursos Multifuncionais/SRMs com Atendimento Educacional Especializado/AEE; computadores com impressora Braille; mesa adaptada para alunos com cadeira de rodas; computador com lupa de apoio para leitura dos alunos com baixa visão e máscara de teclado 'colmeia' para alunos com paralisia cerebral.

Foi observado também que os professores são favoráveis à inclusão escolar, porém afirmam que a reestruturação das escolas é primordial para que a inclusão ocorra efetivamente. Portanto, deve-se atentar para a superação das barreiras arquitetônicas e atitudinais que dificultam o desenvolvimento e a autonomia dos alunos com deficiência, como afirmam as narrativas das professoras a seguir:

Em 2009 a acessibilidade ganhou mais força aqui no Colégio. É possível ver corrimão, tapetes e outros. (Prof. Irma)

Somente este ano o Governo Federal enviou uma verba específica para a acessibilidade arquitetônica. Agora, já possuímos rampas, portas e banheiros adaptados. (Prof. Elza)

Além da necessária reestruturação do espaço escolar, as professoras questionam também a "não capacitação para atuarem nas classes inclusivas." Quanto a esse aspecto, é importante destacar, entre outros documentos oficiais, o Plano Nacional de Educação (BRASIL, 2010), que preconiza a formação continuada de profissionais da educação, tanto professores como funcionários, a qual deverá ser garantida pela equipe dirigente das Secretarias Estaduais e Municipais de Educação através da coordenação e funcionamento dos programas, mantendo-os como ação permanente na busca de parcerias com universidades e demais Instituições de Ensino Superior.

Outros documentos importantes que preconizam a educação inclusiva de alunos com deficiência são a Política Nacional de Educação Especial na perspectiva da Educação Inclusiva/SEESP/ MEC (BRASIL, 2008) e a Declaração de Salamanca e suas Linhas de Ação (UNESCO, 1994), 
que expressam o princípio de inclusão e a preocupação com a garantia de escolas democráticas, cujo objetivo é orientar organizações e governos em suas práticas políticas e pedagógicas, de maneira que acolham os alunos com deficiência, assim como os demais alunos que apresentem ou não deficiência.

\section{Educação inclusiva e o combate à manifestação do preconceito na escola pública}

A experiência com este estudo possibilitou a reflexão sobre por que os professores, em sua maioria, não se sentem preparados para atuar em classes inclusivas, ou seja, por que os professores têm tanto receio de atuar em classes com diferentes alunos?

No decorrer da realização deste estudo, observou-se um discurso quase que unânime entre os professores sujeitos da pesquisa em Duque de Caxias/RJ, ou seja, não se sentem aptos para atuar em classes inclusivas. Foi possível constatar nas experiências com os professores, que sua formação inicial não contemplou as questões relativas à inclusão escolar e nem as relativas aos alunos com deficiência, uma vez que, para atuação em classes inclusivas, faz-se urgente uma formação que contemple o atendimento às necessidades educacionais e às diferenças cognitivas, físicas e sensoriais dos alunos com deficiência na escola pública.

Em resultados de estudos anteriores de Costa (2009, p. 67), "foi possível constatar, nas experiências vividas com os professores, que sua formação inicial não contemplou questões relativas à educação inclusiva, inclusão escolar e aos alunos com deficiência.” E mais, “(...) para atuação em classes inclusivas, faz-se mais necessária uma formação que contemple a sensibilidade dos professores no atendimento às necessidades educativas especiais e à diversidade dos alunos com e sem deficiência na escola pública." Assim, é notório que a inclusão de alunos com deficiência nas classes comuns demanda políticas públicas de formação de professores para que "a educação, ao problematizar a cultura e a diversidade, mas admitindo-as, permite que a subjetividade humana se produza com base na experiência entre diferentes alunos na escola pública” (COSTA, 2009, p. 72). Assim, a discussão sobre a inclusão pode contribuir para tornar a educação mais democrática e apta a acolher a diversidade humana na escola pública.

Diante do exposto até então, para além dos limites sociais e desafios presentes nas narrativas dos professores, é possível afirmar que os alunos com deficiência têm a oportunidade de desenvolverem sua subjetividade nas contradições do cotidiano escolar e portanto, encontram-se desafiados e em constante diferenciação. Isso tem-se revelado como componente da formação dos professores, pois ao lidarem cotidianamente com alunos com diferenças de aprendizagem 
em suas salas de aula, sejam os que têm deficiência ou não, aprendem que os alunos são muito diferentes entre si. Assim, os professores podem ser desafiados a assumir a própria formação em constante enfrentamento com os desafios presentes em sua prática docente.

\section{CONSIDERAÇÕES FINAIS}

De acordo com os resultados obtidos, percebe-se a importância dos professores considerarem a formação dos indivíduos críticos, reflexivos e assim poderem ultrapassar os estreitos caminhos impostos pela deficiência dos alunos e os existentes na escola pública, na qual os alunos considerados deficientes não têm garantia de acesso e permanência de maneira digna e ética. E mais, como recomendado por Costa (2007), é urgente pensar o indivíduo com deficiência considerando sua humanidade que não deve ser negada.

Portanto, neste estudo destacam-se além do compromisso que os professores têm em assumir a organização de escolas inclusivas, combater também o preconceito, pelo menos em sua manifestação, com atitudes pedagógicas acolhedoras e democráticas. A formação dos professores pode contribuir na crítica à realidade social, contemplando questões referentes à inclusão de alunos com deficiência, possibilitando uma educação para o desenvolvimento humano e portanto, permitindo aos professores a criação de ambientes escolares inclusivos na educação dos alunos, com ou sem deficiência.

Para isso, é necessário que os professores percebam-se como autores de sua práxis, enfrentando e combatendo o preconceito e os estereótipos enraizados nas práticas pedagógicas e no pensar, prescindindo, assim, reduzir sua práxis docente às técnicas que banalizam a educação em seus aspectos formativos e humanizadores, considerando que a docência reduzida à técnica não propicia o desenvolvimento de intervenções pedagógicas centradas nas diferentes demandas de aprendizagem dos alunos. É importante também destacar a aproximação dos pais à escola de maneira que possam tornar-se partícipes da educação inclusiva de seus filhos. Há que se pensar na importância da formação dos professores, sobretudo, em uma época em que a educação inclusiva é preconizada como essencial para o enfrentamento e superação do preconceito na escola pública e nos demais espaços sociais.

Concluindo, neste estudo destacou-se a importância e urgência de se analisar e avaliar a formação de professores, com vistas a contribuir na organização da escola pública e suas possibilidades de tornar-se inclusiva, permitindo o acesso à educação dos alunos com deficiência na perspectiva inclusiva. 


\section{REFERÊNCIAS}

ADORNO, T. W. Indústria Cultural e Sociedade. São Paulo: Paz e Terra, 2002, Coleção Leitura, 127p.

Educação e Emancipação. São Paulo: Paz e Terra, 2000, 190p.

Palavras e Sinais: Modelos Críticos 2. Petrópolis: Vozes, 1995, 259p.

BRASIL. Plano Nacional de Educação para o Decênio 2011-2010/PNE. Congresso Nacional, Brasília, DF, 2010.

Política Nacional de Educação Especial na perspectiva da Educação Inclusiva. Ministério da Educação, Secretaria de Educação Especial/SEESP, Brasília, DF, 2008.

COSTA, V. A. da. Políticas públicas, educação e sociedade: Desafios da inclusão. In: MAIA, H. (Org.). Neuroeducação: A relação entre saúde e educação. Coleção Neuroeducação, vol. 1, Rio de Janeiro, WAK Editora, 2011 ${ }^{1}$, p. 59-75.

. Formação de professores e educação inclusiva: Experiências na escola pública. In: COSTA, V. A. da.; CARVALHO, M. B. W. B. de.; MIRANDA, T. G.; DAMASCENO, A. (Orgs.). Políticas públicas e produção do conhecimento em educação inclusiva. Niterói, RJ: Intertexto \& CAPES, $2011^{2}$, p. 31-52.

.; BARCELLOS, C. da S.; TEIXEIRA, E. T. B. F.; FAITANIN, G.P da S. Políticas públicas de educação especial: Experiências de formação e inclusão nas escolas públicas/RJ. In: ZANATA, E. M.; CAPELLINI, V. L. M. F.; LEPRE, R. M.; SILVA, L. F. da. (Orgs.) Formação docente e universalização do ensino: Proposições para o desenvolvimento humano. São Paulo: Cultura Acadêmica Editora, 2011, p. 555-562.

. Educação inclusiva - Para quê? Experiências na escola pública. In: SILVA, M. G. da.; CARVALHO, M. B. W. B. de (Orgs.). Faces da Inclusão. São Luís, EDUFMA, $2010^{1}$, p.121-144.

Políticas públicas en educación: Formación de maestros e inclusión en Brasil. In: CÚPICH, Z. J.; LÓPEZ, S. L. V.; CÓRDOVA, J. de los S. L. (Orgs.). Sujeto, Educación Especial e Integración. Ciudad de México, DF, Editora de la Universidad Nacional Autónoma de México, $2010^{2}$, p. 525-540.

. BARCELlOS, C. da S.; FAITANIN, G. P. S.; ARAUJO, I. R.de. Políticas públicas de educação no Brasil: Experiências dos professores na escola inclusiva. In: CÚPICH, Z. J.; LÓPEZ, S. L. V.; CÓRDOVA, J. de los S. L. (Orgs.). Sujeto, Educación Especial e Integración. Ciudad de México, DF, Editora de la Universidad Nacional Autónoma de México, 2010, p. 509-523. 
- Políticas públicas de educação e formação de professores: Experiências de inclusão dos alunos com deficiência na escola pública. In: CHAVES, I. M. B.; COSTA, V. A. da; CARNEIRO, W. (Orgs.). Políticas públicas de educação: Pesquisas em confluência. Niterói: Intertexto Editora, $2009^{1}$, p. 59-86.

Educação e diversidade: Questões sobre subjetividade. In: BARROS, R. M. M. de (Org.). Subjetividade e Educação: Conexões contemporâneas. Rio de Janeiro: Contra Capa \& FAPERJ, 2009², p. 71-80.

Ensino de História e educação inclusiva: Suas dimensões formativas. In: MONTEIRO, A. M.; GASPARELlO, A. M.; MAGAlHÃES, M. de S. (Orgs.). Ensino de História: Sujeitos, saberes e práticas. Rio de Janeiro, MAUD X FAPERJ, 2007 , p. 253-262.

Os processos de inclusão dos alunos com necessidades educativas especiais: Políticas e Sistemas. Rio de Janeiro, Editora da UNIRIO, 2007², 124p.

CROCHÍK, J. L. Teoria Crítica da Sociedade e Psicologia: Alguns ensaios. Araraquara, SP: Junqueira \& Marin; Brasília, DF: CNPq, 2011, 286p.

Educação para a resistência contra a barbárie. In: Revista Educação, Coleção Especial: Biblioteca do Professor, Adorno pensa a Educação. São Paulo: Editora Segmento, ano $2, n^{\circ} 10$, p.16-25, 2009.

. Preconceito, indivíduo e cultura. São Paulo, Casa do Psicólogo, 2006, 3. a ed.,

$152 \mathrm{p}$.

Preconceito e Formação. In: SILVA, D. J. da.; LIBÓRIO, R. M. C. Valores, preconceito e práticas educativas. São Paulo: Casa do Psicólogo, 2005, p. 17-47.

IBGE. Estimativa da População para 1. ${ }^{\circ}$ de Julho de 2010. Instituto Brasileiro de Geografia e Estatística. Disponível em: http://HYPERLINK"http://www.ibge.gov.br/"www.ibge.gov.br/ home/estatistica/populacao/censo2010/tabelas_pdf/total_populacao_rio_de_janeiro.pdf. Página visitada em 18 de Janeiro de 2011.

UNESCO. Declaração de Salamanca e suas Linhas de Ação sobre Necessidades Educativas Especiais/Espanha. Brasília, DF, 1994.

Submetido em: 05/2012

Aprovado em: 07/2012 